\title{
ELECTROPHYSIOLOGY AND PSYCHOPHYSICS IN OCULAR HYPERTENSION AND GLAUCOMA: EVIDENCE FOR DIFFERENT PATHOMECHANISMS IN EARLY GLAUCOMA
}

\author{
SIMON T. RUBEN ${ }^{1}$, ROGER A. HITCHINGS $^{1}$, FRED FITZKE ${ }^{2}$ and GEOFFREY B. ARDEN ${ }^{2}$ \\ London
}

\begin{abstract}
SUMMARY
It is not clear whether glaucomatous optic nerve damage is the end result of one pathological process or whether there are several mechanisms by which the final disease is manifest. The use of electrophysiological and psychophysical tests which measure the function of specific subdivisions of the visual pathways have been shown to be of use in the early diagnosis of glaucoma. In addition these results may help to elucidate the mechanisms of loss of visual function in patients with early glaucoma. One hundred and ninety-three patients with ocular hypertension (intraocular pressure $>\mathbf{2 4} \mathbf{m m H g}$, with normal visual fields and optic discs), 30 with glaucoma and 35 controls underwent pattern electroretinogram (PERG), peripheral colour contrast thresholds, motion detection thresholds (MDT) and Humphrey automated visual fields at the same visit. For each test there was a significant proportion of patients with abnormal results as has been found in previous studies of these techniques. However, there was a significant lack of correlation between the groups with only a small number of patients having abnormalities on more than one test. Of the patients demonstrating abnormal PERGs, 36\% had abnormal colour contrast and $32 \%$ abonormal MDT, but only $15 \%$ were abnormal on both tests. Early glaucomatous damage may be focal or diffuse in nature. Similarly there may be preferential damage to ganglion cells subserving different visual functions or damage at different retinal layers. The results lend support to these hypotheses and give further evidence that more than one pathomechanism may be involved early in the glaucomatous process.

Although the mechanism of early glaucomatous visual

From: 'Moorfields Eye Hospital, London; ${ }^{2}$ Institute of Ophthalmology, London, UK.

Correspondence to: $\mathrm{Mr}$ Simon Ruben, Department of Ophthalmology, Coventry and Warwickshire Hospital, Stoney Stanton Road, Coventry CV1 4FH, UK.
\end{abstract}

loss is not fully understood, much evidence has been accumulated from psychophysical testing, ${ }^{1-6}$ electrophysiological testing, ${ }^{7-9}$ histological examination of post-mortem specimens of optic nerve and retina, ${ }^{10-12}$ and from clinical evaluation of the optic disc. ${ }^{13-16}$

The primate anterior visual system is divided and remains segregated through several synapses in the visual system into pathways pertaining to colour and spatial resolution on the one hand and high contrast sensitivity and temporal resolution on the other. ${ }^{17.18}$ In addition, each of these two pathways is subserved by a different class of ganglion cell: those with large-diameter axons (fast) projecting to the magnocellular layer of the lateral geniculate body (LGB) for motion and small-diameter axons (slow) projecting to the parvocellular areas of the LGB for colour perception and fine vision. ${ }^{17.19}$

Histological studies have provided evidence that the large-diameter fibres are damaged early in the glaucomatous process. ${ }^{11.12}$ Psychophysical tests of motion detection and flicker sensitivity have been investigated and provide evidence in support of these histological findings in patients with established glaucoma and ocular hypertension. ${ }^{2.6 .20-23}$

On the other hand, there is also much evidence in support of early damage to other parts of the anterior visual pathways. Colour vision testing has been investigated in glaucoma for many years but until recently has not been practical in clinical terms because of low sensitivity and the long test time required. With newer computerised colour testing systems quick and reliable assessment of colour function can be carried out. ${ }^{1,5,24}$ In addition, blueon-yellow and short-wavelength perimetry has been shown to detect focal glaucomatous defects more reliably than conventional methods. ${ }^{25-27}$

Electrophysiological tests can give a more objective measure of optic nerve function because they are not 
influenced to the same degree by cognitive factors or the motor skills of the subject as compared with psychophysical tests. The pattern electroretinogram (PERG) has been shown to be a sensitive measure of optic nerve function and has high sensitivity and specificity for discriminating between normal and glaucomatous patients. ${ }^{28.29}$ The finding that a high proportion of ocular hypertensive patients give abnormal PERG results ${ }^{30}$ would suggest that there may be diffuse loss of ganglion cell function occurring before the onset of perimetrically discernible focal defects.

In this article we review the results of a cohort of 193 ocular hypertensive patients who underwent electrophysiological (PERG) and psychophysical testing (movement displacement thresholds (MDT), peripheral colour contrast thresholds). By examining the relationships between the different tests hypotheses about the mechanism of early damage can be discussed.

\section{PATIENTS AND METHODS}

One hundred and ninety-three ocular hypertensive patients (mean age 60 years), 30 glaucoma patients and 35 controls underwent electrophysiological and psychophysical testing after full informed consent had been obtained. All ocular hypertensive patients had intraocular pressures (IOP) $\geqslant 24 \mathrm{mmHg}$ and had normal Humphrey visual fields using the criterion of no points of the central 24-2 programme (excluding the uppermost row) depressed by greater than $5 \mathrm{~dB}$ compared with agematched controls. All tests were carried out in random order and before commencement of medical treatment.

\section{Electrophysiology}

The PERG to an alternating chequerboard pattern with near $100 \%$ contrast was performed as described in detail in previous reports from this department. ${ }^{28.29}$ The stimulus area measured $22 \times 16$ degrees with a check size of $30^{\prime}$. Transient responses using a pattern reversal frequency of 6 RPS and steady-state responses recorded at 16 RPS were measured.

\section{Peripheral Colour Contrast Threshold Testing}

The equipment and method for measuring peripheral colour contrast have been described in detail in previous publications. ${ }^{5.31}$ The equipment consists of a high-resolution colour monitor driven by a computer with special graphics card and software. The image on the screen was a central white fixation spot, a uniform background of 16 $\mathrm{cd} / \mathrm{m}^{2}$, and a colour contrast annulus concentric with a fixation spot. Annulus and background were of the same luminance and this varied slightly depending on the subject's flicker matches. The distance between screen and cornea was fixed at $45 \mathrm{~cm}$. The annulus had a radius of $12.5^{\circ}$ in the extra-macular field and a width of $1^{\circ}$ of arc.

The test involved the removal of a $45^{\circ}$ segment of the annulus in one of four quadrants: right or left upper, right or left lower. The patient had to identify the correct quadrant. Threshold colour contrast was obtained with a modi- fied binary search technique previously described. What was measured amounted to an average colour contrast threshold in the entire annular zone of the retinal image of the stimulus.

Only the peripheral colour contrast thresholds for the tritan axis were determined as there is evidence that there is selective loss of blue-yellow sensitivity in ocular hypertensive patients. ${ }^{5}$

\section{Peripheral Movement Displacement Thresholds}

The MDT test used has been described in detail previously. ${ }^{2}$ The test uses a 2 minute by 2 degree computergenerated vertical line. The background and stimulus luminance were $7 \mathrm{~cd} / \mathrm{m}^{2}$ and $27 \mathrm{~cd} / \mathrm{m}^{2}$ respectively. The background subtended $8^{\circ} \times 10^{\circ}$ and was viewed at $1.24 \mathrm{~m}$. Measurements were made at a single location at $15^{\circ}$ in the temporal field, on the $330^{\circ}$ meridian, just above the blind spot. Frequency-of-seeing curves were constructed by presenting the moving target (frequency $2.5 \mathrm{~Hz}) 10$ times at 0-18 minutes of arc displacements (in random order). The data were analysed by probit analysis to give a $50 \%$ value of movement displacement threshold.

Values for these tests in normal and glaucomatous eyes have been investigated previously in this department ${ }^{2.5 .29}$ and have been used to establish cut-off levels between normal and abnormal test results which are shown in Table I. All tests have been shown to give significantly abnormal results in glaucomatous eyes, with lesser, but significantly abnormal results in ocular hypertensive eyes.

\section{RESULTS}

All ocular hypertensive patients had an IOP of $24 \mathrm{mmHg}$ or greater (mean $26 \mathrm{mmHg}$ ) measured on at least two occasions. The average of three consecutive IOP measurements was used.

The means $( \pm S D)$ are shown for the results of the electrophysiological and psychophysical tests in Table II. The numbers of ocular hypertensive patients with abnormal results on each test are shown in Table III.

In order to examine the relationship between the different tests, a Venn diagram has been constructed showing the number of patients with abnormal results on each test (Fig. 1). In a similar way the number of controls with abnormal tests and glaucoma patients with normal tests are shown.

As has been found in previous studies the number of patients with abnormal PERG results is higher than would be expected from the natural history of ocular hypertension. In contrast, the number of patients with abnormal results on peripheral colour contrast testing and MDT was more in keeping with the number of patients likely to show visual field changes in the future. It can be seen that of 84 patients with either abnormal colour or motion tests only $18(21 \%)$ were abnormal on both. If only the patients with abnormal PERG results are studied then they are split fairly evenly into three groups: abnormal colour (17), abnormal motion (13) and abnormal on both (14). Of the glaucoma patients only 1 patient had normal results for all 
Table I. Values of movement displacement thresholds (MDT), peripheral colour contrast thresholds and pattern electroretinogram (PERG) previously reported from this department

\begin{tabular}{lccc}
\hline & Control & OHT & Glaucoma \\
\hline MDT $(\%$ threshold $)$ & $3.23 \pm 1.9$ & $5.5 \pm 3.14$ & $9.7 \pm 4.9$ \\
$\begin{array}{l}\text { Colour contrast } \\
(\% \text { threshold })\end{array}$ & $14 \pm 3$ & $21.1 \pm 6.9$ & $62.5 \pm 26.3$ \\
PERG $(\mu \mathrm{V})$ & 4.36 & $\begin{array}{c}\text { (medium risk) } \\
3-3.55\end{array}$ & 1.66 \\
\hline
\end{tabular}

From Fitzke et al., ${ }^{2} \mathrm{Yu}$ et al. ${ }^{5}$ and O’Donoghue et al. ${ }^{29}$

Values are the mean \pm SD

OHT, ocular hypertensives.

three tests whereas none of the controls had all three tests abnormal and only 2 had two abnormal test results.

\section{DISCUSSION}

During the last decade there has been a huge increase in the search for alternative methods for the early detection of glaucoma. This has been fuelled partly by the finding that even automated perimetry may remain normal in the presence of significant ganglion cell damage. ${ }^{\bullet}$ In addition, the ocular hypertensive population continues to grow and the majority of ophthalmologists continue to monitor IOP and cup:disc ratio as these have been shown to be the critical risk factors for development of glaucoma. ${ }^{32}$ Although IOP has been shown to be an important risk factor, it does not on its own allow us to predict which ocular hypertensive patients will develop glaucoma in the future (some of whom will already have subclinical optic nerve damage), as up to a third of glaucoma patients present with IOP in the normal range,,$^{30,33}$ and it has long been recognised that patients with high IOP may not develop glaucoma. ${ }^{34}$

Alternative methods for glaucoma screening or for monitoring ocular hypertensive patients depend upon testing the integrity of different parts of the anterior visual pathways, either in isolation or as a whole. From our knowledge of the anatomy and physiology of the visual system it is possible to define which pathways are being tested by any particular method. From our results, and those of other authors, it is clear that the pathomechanism of early glaucoma is not confined to damage to one particular element of the visual system, but that either different cell groups may be more sensitive to damage in certain populations, or there are several disease processes involved.

It has been shown histologically that large ganglion cells are damaged early and selectively in the disease pro-

Table II. Results for movement displacement thresholds (MDT), peripheral colour contrast thresholds and pattern electroretinogram (PERG)

\begin{tabular}{lrcc}
\hline & \multicolumn{1}{c}{ Control } & OHT & Glaucoma \\
\hline MDT $(\%$ threshold $)$ & $4.9 \pm 1.9$ & $6.1 \pm 2.9$ & $8.0 \pm 3.5$ \\
$\begin{array}{l}\text { Colour contrast } \\
(\% \text { threshold })\end{array}$ & $17.9 \pm 9.9$ & $21.8 \pm 10.8$ & $39.3 \pm 22.8$ \\
PERG $(\mu \mathrm{V})$ & $3.74 \pm 0.9$ & $3.07 \pm 1.28$ & $2.01 \pm 1.44$ \\
\hline
\end{tabular}

Values are the mean \pm SD.

OHT, ocular hypertensives. cess. ${ }^{11.12}$ This is the rationale behind the use of motion detection as an early predictor of optic nerve damage, as the magnocellular pathway subserves this aspect of visual processing. ${ }^{17,19}$ Motion tests have been shown to be significantly impaired in glaucoma and in a proportion of ocular hypertensive patients. ${ }^{2.21 .23 .35}$ There is also correlation with other psychophysical and electrophysiological tests and with optic nerve morphology. ${ }^{16.36}$ However, the correlations are by no means perfect. This is partly explained by the psychophysical nature of many tests, which are influenced by the cognitive and motor skills of the patient. It is impossible to take the effect of this into consideration when applying statistics to the raw data derived from such tests. Furthermore, normal and abnormal values for psychophysical tests tend to have wide ranges.

If damage to the magnocellular part of the anterior visual system, is not the universal mechanism for early glaucomatous damage then we would not expect to see all patients with abnormal optic nerve function on electrophysiology exhibit abnormal MDT results. This is borne out by our results. There is an overlap between colour thresholds (predominantly parvocellular function) and MDT (predominantly magnocellular), with many patients giving abnormal results on either one or other, but few on both tests.

Because of the segregation of the visual pathways we are able to isolate specific functions by psychophysical techniques. It is clear that in early glaucoma there is likely to be damage to both magno- and parvocellular pathways either separately or in combination, and that both largeand small-diameter ganglion cells are affected early in the disease, but to different degrees. It will depend on each individual which test will become abnormal first and this will in turn depend not only on the mechanism of damage but also on the higher mental functions involved in each test. As the disease process advances the test results become abnormal for all aspects of visual function as can be seen from the almost universally abnormal results found in patients with established glaucoma.

It is not only the type of cells damaged first which has been questioned. Is there diffuse loss of ganglion cells or are all field defects preceded by focal loss only? Electrophysiological results support the hypothesis of diffuse loss. The PERG measures a massed ganglion cell response ${ }^{37.38}$ and a small focal defect would be unlikely to give such a significant drop in response as is found in patients with such defects and in a proportion of ocular hypertensive patients with normal visual fields.

Table III. Number of ocular hypertensive eyes with test values considered to be abnormal for movement displacement thresholds (MDT), peripheral colour contrast thresholds and pattern electroretinogram (PERG)

\begin{tabular}{lcc}
\hline & $\begin{array}{c}\text { No. with abnormal } \\
\text { test } \\
(n=193)\end{array}$ & $\begin{array}{c}\text { \% with abnormal } \\
\text { test }\end{array}$ \\
\hline MDT & 49 & 25 \\
Colour contrast threshold & 53 & 27 \\
PERG & 84 & 43 \\
\hline
\end{tabular}



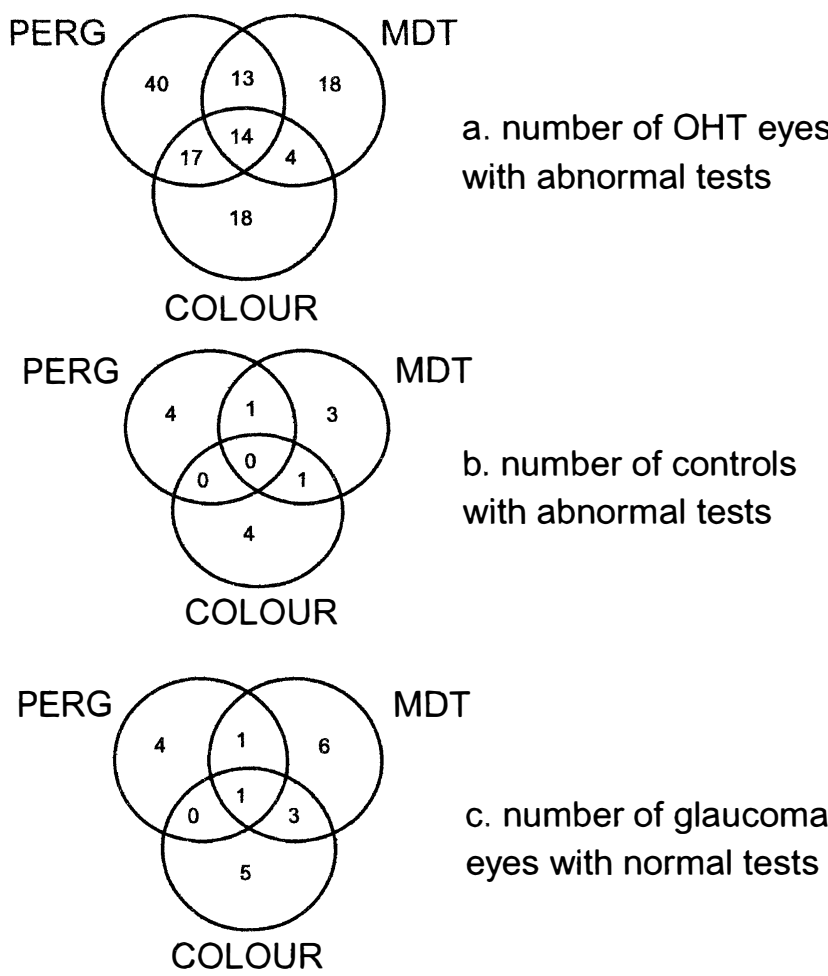

c. number of glaucoma eyes with normal tests

Fig. 1. Venn diagrams illustrating the number of patients with abnormal test results and their relation to each other (total $n=193$ ). PERG, pattern electroretinogram; Colour, peripheral colour contrast thresholds; MDT, movement displacement thresholds.

A significant proportion of ocular hypertensive patients show abnormalities in one or more of the tests performed. If damage is occurring in both magnocellular and parvocellular divisions of the anterior visual pathways, which is clearly the case, the extent to which damage to one exceeds the other can not be quantified and is likely to vary from one person to another. It is therefore unlikely that a single test that measures only one part of the visual system will reliably detect all cases of early ganglion cell damage in ocular hypertensive eyes. We should therefore utilise a combination of psychophysical tests such as colour contrast thresholds together with MDT, or alternatively employ an electrophysiological test that measures total ganglion cell function (PERG). Depending on whether the object is, on the one hand, to increase the specificity of glaucoma screening or, on the other, to predict those ocular hypertensive patients most at risk, we can utilise either the combination of tests most appropriate to the task or those available in the clinic.

Key words: Electrophysiology, Glaucoma, Ocular hypertension, Psychophysics.

\section{REFERENCES}

1. Gunduz K, Arden GB, Perry S, Weinstein G, Hitchings RA. Colour vision defects in ocular hypertension and glaucoma: quantification with a computer driven colour television system. Arch Ophthalmol 1988;108:929-35.

2. Fitzke FW, Poinoosawmy D, Nagasubramanian S, Hitchings RA. Peripheral displacement thresholds in glaucoma and ocular hypertension. Perimetry Update 1988; [1988/1989]:399-405.
3. Drance SM, Lakowski R, Schulzer M, Douglas GR. Acquired colour vision changes in glaucoma. Arch Ophthalmol 1981;99:829-31.

4. Johnson CA, Adams AJ, Casson EJ, Quigg JM. Can short wavelength sensitivity losses predict the development of glaucomatous visual field defects? Invest Ophthalmol Vis Sci 1991;32:1191

5. Yu TC, Falcao-Reis FM, Spileers W, Arden GB. Peripheral Colour Contrast: a new screening test for pre-glaucomatous visual loss. Invest Opthalmol Vis Sci 1991;32:2779-89.

6. Joffe KM, Raymond JE, Crichton A. Motion perimetry in glaucoma. Invest Ophthalmol Vis Sci 1991;32:1 103.

7. Maffei L, Fiorentini A. Electroretinographic responses to alternating gratings before and after section of the optic nerve. Science 1984;211:953-5.

8. May JG, Ralston JV, Reed JL, van Dyk HJL. Loss in patternelicited electroretinograms in optic nerve dysfunction. Am J Ophthalmol 1982;93:418-22.

9. Ringens PJ, Viifvinkel-Bruinenga S, Van Lith GHM. The pattern elicited electroretinogram. I. A tool in the early detection of glaucoma. Ophthalmologica 1986;192:171-5.

10. Quigley HA, Dunkelberger BS, Green WR. Retinal ganglion cell atrophy correlated with automated perimetry in human eyes with glaucoma. Am J Ophthalmol 1989;107: 453-64.

11. Quigley HA, Dunkelberger GR, Green WR. Chronic human glaucoma causing selectively greater loss of large optic nerve fibres. Ophthalmology 1988;95:357-64.

12. Quigley HA, Sanchez RM, et al. Chronic glaucoma selectively damages large optic nerve fibres. Invest Ophthalmol Vis Sci 1987;28:913-20.

13. Jonas JB, Gusek GC, Naumann GOH. Optic disc morphometry in chronic open angle glaucoma. I. Morphometric intrapapillary characteristics. Graefes Arch Clin Exp Ophthalmol 1988;226:522-30.

14. Sommer A, Pollack I, Maumenee AE. Optic disc parameters and the onset of glaucomatous field loss. II. Static screening criteria. Arch Opthalmol 1979;97:1449-54.

15. Airaksinen PJ, Drance SM, Schulzer M. Neuroretinal rim area in early glaucoma. Am J Ophthalmol 1985;99:1-4.

16. Drance SM. Correlation of optic nerve and visual field defects in simple glaucoma. Trans Ophthalmol Soc UK 1975;95:288.

17. Livingstone MS, Hubel DH. Psychophysical evidence for separate channels for the perception of form, colour, movement and depth. J Neurosci 1987;7:3416-3468.

18. Hubel DH, Livingstone MS. Segregation of form, colour and stereopsis in primate area 18. J Neurosci 1987;7: $3378-415$

19. Schiller HN, Logothetis NK, Charles ER. Functions of the colour-opponent and broad-band channels of the visual system. Nature 1990;343:68-70.

20. Tytla ME, Trope GE, Buncic RJ. Flicker sensitivity in treated ocular hypertension. Ophthalmology 1990;97: 36-44.

21. Bullimore M, Wood, J, Swenson K. Motion perception in glaucoma. Invest Ophthalmol Vis Sci 1993;34:3526-33.

22. Wu J, Fitzke F, Poinoosawmy D, Hitchings R. Four years follow-up of the fellow eye of unilateral glaucoma patients using motion sensitivity. Invest Ophthalmol Vis Sci 1994; 35:2185.

23. Watkins R, Buckingham T. Motion perception hyperacuity is abnormal in primary open glaucoma and ocular hypertension. Invest Ophthalmol Vis Sci 1991;32:1103.

24. Falcao-Reis FM, Spileers W, O’Sullivan F, Arden GB, et al. Macular colour contrast sensitivity in ocular hypertension and glaucoma. Br J Ophthalmol 1991;75:598-602.

25. Sample PA, Mantzioros N, Fechtner R, Weinreb RN. Progressive colour visual field loss in eyes with primary open angle glaucoma. Invest Ophthalmol Vis Sci 1991;32:1193. 
26. Johnson C, Casson E, Shapiro L. Progression of glaucomatous visual field loss over five years: a comparison of whiteon-white and blue-on-yellow perimetry. Invest Ophthalmol Vis Sci 1992;33:1384.

27. Johnson C, Brandt J, Khong A, Adams A. Short wavelength automated perimetry (SWAP) in low, medium and high risk ocular hypertensives. Invest Ophthalmol Vis Sci 1984;35: 2188.

28. Weinstein GW, Arden GB, Hitchings RA, et al. The pattern electroretinogram (PERG) in ocular hypertension and glaucoma. Arch Ophthalmol 1988;106:928-31.

29. O'Donoghue E, Arden G, O'Sullivan F, et al. The pattern electroretinogram in glaucoma and ocular hypertension. $\mathrm{Br}$ J Ophthalmol 1992;76:387-94.

30. Klein B, Klein R, Sponsel W, et al. Prevalence of glaucoma. The Beaver Dam eye study. Ophthalmology 1992;99: 1499-504.

31. Arden GB, Gunduz K, Perry S. Colour vision testing with a computer graphics system. Clin Vis Sci 1988;2:203.

32. Yablonski ME, Zimmerman TJ, Kass MA, Becker B. Prog- nostic significance of optic disc cupping in ocular hypertensive patients. Am J Ophthalmol 1980;89:585-92.

33. Hollows FC, Graham PA. Intraocular pressure, glaucoma and glaucoma suspects in a defined population. $\mathrm{Br} \mathrm{J}$ Ophthalmol 1966;50:570-86.

34. Elshnig A. Glaucoma without high pressure and high pressure without glaucoma. Z Augenklinik 1924;52:287-96.

35. Wu X, Wormald R, Fitzke FW, Poinoosawmy D, et al. Laptop computer perimetry for glaucoma screening. Invest Ophthalmol Vis Sci 1991:32:810.

36. Drance SM, Airaksinen PJ, Price M. et al. The use of psychophysical, structural and electro-diagnostic parameters to identify glaucomatous damage. Graefes Arch Clin Exp Ophthalmol 1987;225:365.

37. Arden GB, Vaegan, Hogg CR. Clinical and experimental evidence that the pattern e.r.g. is generated by the innermost retinal layers. Ann NY Acad Sci 1982;388:580-601.

38. Sieving PA, Linsenmeir RA, Steinberg RH. Current source density (CSD) analysis shows main pattern ERG (PERG) source in proximal retina. Invest Ophthalmol Vis Sci 1984; 25(Suppl):259. 